Int. J. Dev. Biol. 51: 409-413 (2007)

doi: $10.1387 / \mathrm{ijdb} .072273 \mathrm{tm}$

Short Communication

\title{
Analysis of Netrin 1 receptors during inner ear development
}

\author{
TANJA MATILAINEN, MAARJA HAUGAS, JORDAN A. KREIDBERG ${ }^{1,2}$ and MARJO SALMINEN* \\ Developmental Biology Program, Institute of Biotechnology, University of Helsinki, Finland, 'Department of Medicine, The Children's \\ Hospital and ${ }^{2}$ Department of Pediatrics, Harvard Medical School, Boston, MA, USA
}

\begin{abstract}
Netrin 1 plays key roles in axon guidance and neuronal migration during central nervous system (CNS) development. Outside the CNS, Netrin 1 has been shown to be involved in epithelial morphogenesis of various organs. We have shown that Netrin 1 is essential for inner ear semicircular duct formation, but the involvement of Netrin 1 receptors in this process has remained unknown. Netrin 1 receptors include members of the Deleted in colorectal cancer (Dcc), Unc5-homologue and integrin families. Here we have analysed the expression of these receptor genes during inner ear development and verified the inner ear phenotypes of several receptor mutant mice. Special interest was directed to receptors that could cooperate with Netrin 1 during semicircular duct formation. We show that Neogenin (Neo1), Unc5c as well as integrin $\beta 1$ (Itgb1) are expressed in periotic mesenchyme, while Dcc, Unc5b, Unc5c, Itga3, Itga6 and Itgb1 are expressed in different parts of the otic epithelium. In spite of the broad and strong expression of several receptors in ear region, none of the analysed receptor mutant embryos showed any defects in inner ear development.
\end{abstract}

KEY WORDS: epithelial morphogenesis, semicircular duct, Dcc, Unc5, integrin

\section{Netrin1 in the inner ear}

In mouse, semicircular ducts start to grow out from the dorsal otic vesicle as two-layered pouches of the dorsal epithelium around embryonic day (E) 10.5-11.0. These pouches then flatten and the opposing epithelial layers meet in the middle to form socalled fusion plates. The underlying basement membrane is disrupted, which allows the fusion plate cells to detach and form a single cell-layer that is subsequently cleared leaving behind the newly formed semicircular ducts at E12.5-13.0 (Martin and Swanson, 1993). The laminin-related secreted protein Netrin1 (Ntn1) is essential for the formation of the semicircular ducts. In Ntn1-/- embryos, the detachment of the fusion plate basement membrane does not occur properly. In addition, the proliferation of the adjacent mesenchyme is decreased and the two opposing fusion plate epithelia cannot approach each other normally (Salminen et al., 2000). These defects result in the complete lack of posterior and lateral semicircular ducts. The superior duct forms but fails to grow to its normal size and shape (Salminen et al., 2000).

Ntn1 expression in inner ear initiated at late E10.5 in the dorsolateral wall of the otic vesicle marking the future fusion plate area of the superior and posterior semicircular ducts (data not shown). At E11.5-12.5, Ntn 1 was strongly expressed in the areas destined to form the fusion plates but was excluded from the distal ends of the duct outgrowths. Expression extended also ventrally to the future saccule, utricle and cochlear duct. When the semicircular ducts had formed and the fusion plate cells cleared, Ntn 1 expression was maintained in the inner edges of the ducts (Fig. 1A,B; Salminen et al., 2000). At E18.5, Ntn1 continued to be expressed in the inner edges of the semicircular ducts and in the non-sensory epithelium of the utricle and saccule. No expression could be detected in any of the sensory epithelia or the vestibulocochlear ganglion (Salminen et al., 2000). In postnatal cochlea, Ntn1 expression was restricted to Reissner's membrane (Fig. 1T).

Ntn1 protein has been localised on the fusion plate forming cells and in the underlying basement membrane (Salminen et al., 2000). Ntn1 is also thought to diffuse and form a concentration gradient at least in the developing chicken spinal cord (Kennedy et al., 1994) and therefore, Ntn1 could interact with receptors expressed by the fusion plate epithelium itself and by the adjacent epithelial or mesenchymal cells.

\section{Dcc family members in the inner ear}

Ntn1 has been shown to bind to transmembrane proteins belonging to the Deleted in colorectal cancer (Dcc) and Unc-5 homologue (Unc5) families (Reviewed in Barallobre et al., 2005).

Abbreviations used in this paper: Ntn1, Netrin1; Dcc, Deleted in colorectal cancer; Neo1, Neogenin, Unc5a-d, Unc5-homologue a-d; Itga, integrin alpha; Itgb, integrin beta; Pn1, postnatal day 1 .

\footnotetext{
*Address correspondence to: Marjo Salminen. Institute of Biotechnology, University of Helsinki, Viikinkaari 9, 00710 Helsinki, Finland. Fax: +358-9-191-59-366. e-mail: marjo.salminen@helsinki.fi
} 
Fig.1. Expression of Dcc and Unc5 family members in the inner ear. $R a$ dioactive RNA in situ hybridisation analysis of the expression of Ntn1 (A,B), Dcc (C), Neo1 (D), Unc5a (E), Unc5d (F,G), Unc5c (I-K) and Unc5b (L-P) performed on serial paraffin sections from E11.5 $(A, E, I), E 12.5$ (B-D, F, J,L,M), E14.5 $(G, K, N)$ and $E 18.5(O, P)$ wild type mouse embryos. Arrow in (B) points to Ntn1 expression in the inner edge of a newly formed semicircular duct. Arrows in (G) point to Unc5d expression in the loose mesenchyme surrounding the utricle. Arrows in (O) point to Unc5b expression beneath the sensory organs. Arrow in $(P)$ points to the organ of Corti area. The plane of sections is indicated in $\mathbf{( H )}$. Analysis of Unc5b expression in sections from wild type $(\mathbf{Q})$ and Ntn1-/littermate embryos (R) at E11.5 showing that $U n c 5 b$ remains restricted to the tip of the outgrowing semicircular duct (arrows). The expression domains are visualized as computer superimpositions of bright-field views showing the hematoxyline stained serial sections and dark-field views revealing the signal grains in red false-colour. No specific signal was detected with the Ntn 1 sense probe at E12.5 (S). Radial vibratome sections through the cochleas of oneday old (Pn1) mice analysed with DIGlabelled Ntn1 (T) or Unc5b probes (U,V). (V) A higher magnification of the organ of Corti area in $(U)$. Scale bars in (A-G) and (I-S) represent $50 \mu \mathrm{m}$; in (T-V) $20 \mu \mathrm{m}$. Abbreviations: c, cochlea; C, Claudius cells; cg, cochlear ganglion; cm, condensing mesenchyme; cr, crista; ed, endolymphatic duct; fp, fusion plate epithelium; GER, greater epithelial ridge; $H$, Hensen's cells; ihc, inner hair cells; Id, lateral semicircular duct; ms, macula of the saccule; mu, macula of the utricle; oC, organ of Corti; ohc, outer hair cells; Pi, Pillar cells; pm, periotic mesenchyme; Rm, Reissner's membrane; s, saccule; sd, superior semicircular duct; u, utricle; us, utriculo-saccular space; vg, vestibular ganglion; wt, wild type; a, anterior; $p$, posterior; $v$, ventral; $d$, dorsal.
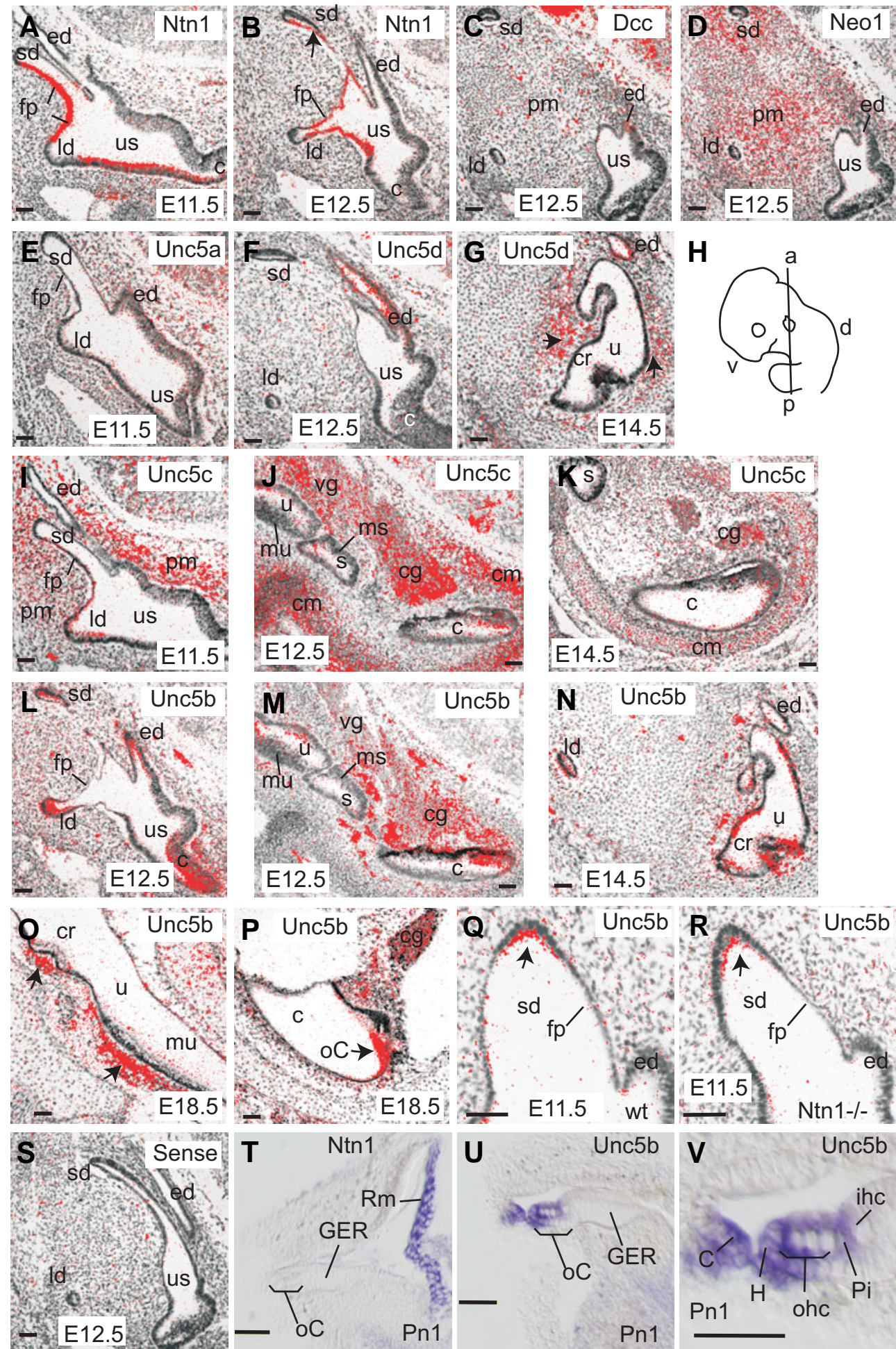

During embryonic development, Dcc was strongly expressed in hindbrain but only a weak expression could be detected in the inner ear at E12.5, in the tip of the endolymphatic duct (Fig. 1C and data not shown). In addition, no defects were observed in the ears $(\mathrm{n}=4)$ of $D c c$-/-embryos (data not shown) strongly suggesting that Ntn1/Dcc signalling does not play a major role in inner ear morphogenesis.
The close relative to Dcc, Neogenin (Neo1), was strongly expressed all over the dorsal periotic mesenchyme at all stages analysed (E11.5-18.5) while no expression in the epithelium could be detected (Fig. 1D and data not shown). The expression of Neo1in the mesenchyme adjacent to the fusion plate basement membrane suggested that it could participate in Ntn1 dependent signalling to promote proliferation and/or survival of the mesen- 
chyme. However, no morphological defects were observed in Neo1 deficient inner ears $(n=2)$ at E17.5 (data not shown) suggesting again that the Dcc family receptors do not play important morphogenetic roles during inner ear development.

\section{Unc5 family members in the inner ear}

While no significant expression of Unc5a was detected at E11.5-18.5 (Fig. 1E and data not shown) the three other Unc5family members were expressed in developing inner ear in variable levels and locations. Unc5d was transiently expressed in the endolymphatic duct at E11.5-14.5 (Fig. 1F,G). At E12.5-18.5 expression was detected also in a subset of vestibular and cochlear ganglion cells (data not shown). Especially strong expression at E14.5 was observed in the loose mesenchyme surrounding the vestibule (Fig. $1 \mathrm{G}$ ). These mesenchymal cells will be removed during E14.5-18.5 to generate the perilymphatic space between the membranous labyrinth and the bony otic capsule.

Unc5cshowed a mainly mesenchymal expression in inner ear all through the development. It was already expressed in the mesenchyme surrounding the otic vesicle at E10.5 as well as in a small dorso-lateral domain of the vesicle epithelium (data not shown). At E11.5-14.5 strongest expression was detected in the periotic mesenchyme and the vestibular and cochlear ganglia (Fig. 1I-K). The mesenchymal expression became especially prominent during otic capsule condensation suggesting a role in this process (Fig. 1J,K). In otic epithelium, strongest expression was observed in the distal end of the lateral semicircular duct (Fig. 11). Weak expression could also be detected in the distal parts of the superior and posterior ducts and the thin non-sensory lateral wall of the cochlear duct (Fig. 1I-K and data not shown). No expression could be observed anymore in the inner ear at E18.5 (data not shown). In spite of the strong mesenchymal expression, no defects in inner ear morphology could be observed in Unc5c/- embryos $(\mathrm{n}=2)$ at $\mathrm{E} 18.5$ (data not shown).

From all Unc5 receptors, Unc5b showed the broadest expression pattern. Unc5b was detected at E10.5 in dorso-lateral and ventral parts of the otic vesicle as well as in the endolymphatic duct outgrowth (data not shown). At E11.5-12.5 Unc5b was strongly expressed in the distal parts of the outgrowing semicircular duct plates and remained there in the newly formed semicircular ducts until E14.5 (Fig. 1L,N and data not shown). Also in the endolymphatic duct, Unc5b expression was detected until E14.5 (Fig. $1 \mathrm{~N}$ ).

Unc5b was the only Ntn1 receptor expressed in the otic sensory epithelia. Strong expression was observed in developing semicircular duct cristae at E12.5-14.5 (Fig. $1 \mathrm{~N}$ and data not shown) whereas no expression could be detected in the sensory areas of the saccule and the utricle (Fig. 1M,O). Instead, Unc5b was expressed in non-sensory parts of the utricle (Fig. $1 \mathrm{M}, \mathrm{N})$ as well as in mesenchymal cells underlying the different sensory epithelia of the vestibule (arrows in Fig. 10). In the cochlea, Unc5bexpression was confined to the medial pre-sensory epithelium and the adjacent mesenchyme at E12.5-14.5 (Fig. 1L,M) and at E18.5-Pn1 strong expression was detected in the hair and supporting cells of the organ of Corti as well as in the neighbouring Hensen's and Claudius cells (Fig. 1P,U,V). Strong expression of Unc5b was also observed in vestibular and cochlear ganglion cells (Fig. 1M,P).

Interestingly, at all stages analysed, the expression of Unc5b
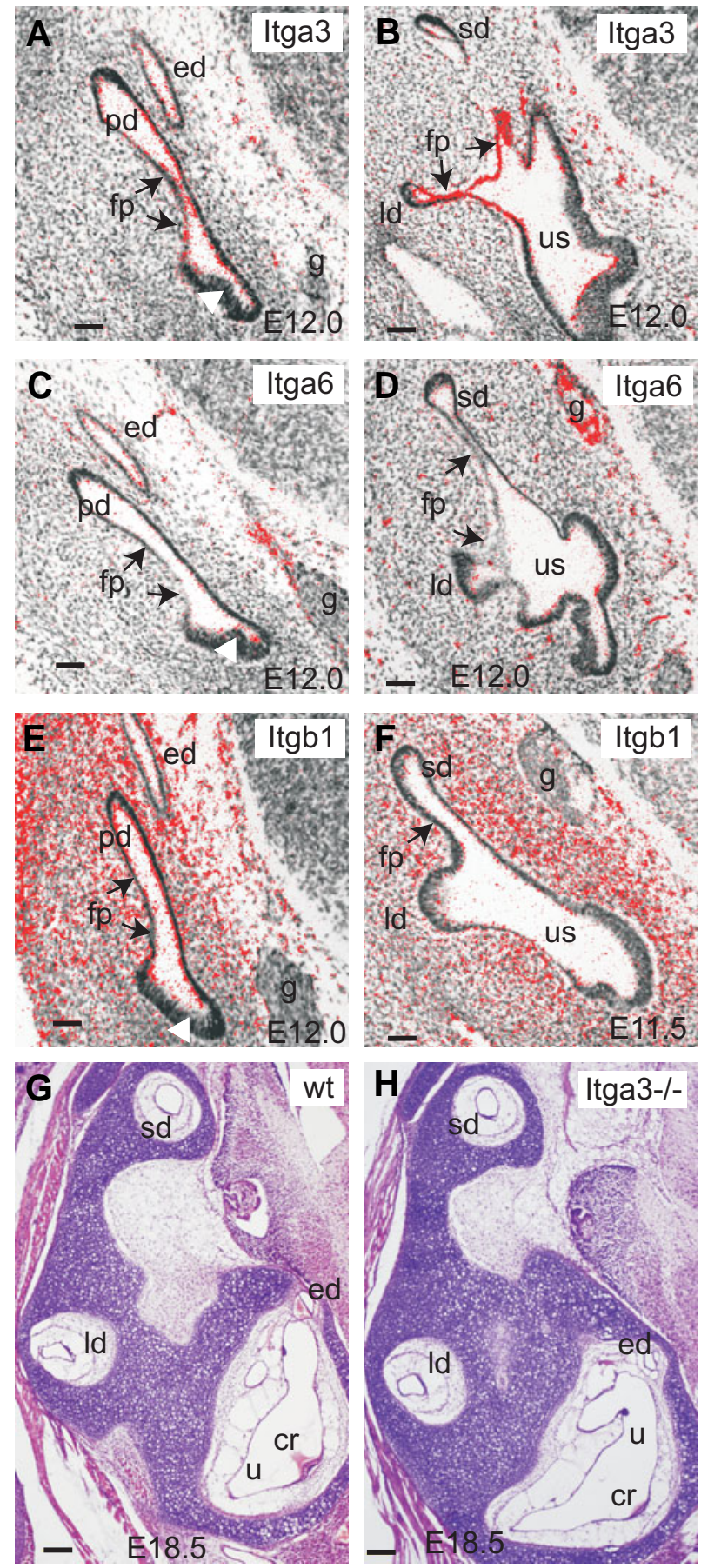

Fig. 2. Integrin subunits in the inner ear. RNA in situ hybridisation analysis of Itga3 (A,B), Itga6 (C,D) and ltgb1 (E, F) expression on sections from E12.0 (A-E) and E11.5 (F) mouse embryos. Arrows point to the fusion plate areas where Itga3 and Itgb1 signals could be detected. White arrowheads point to the thick presensory areas where Itga6 and Itgb1 were weakly expressed. Hematoxylene-eosin stained paraffin sections from E18.5 wild type (G) and Itga3-/- (H) littermates showing that no obvious differences were detectable in inner ear structures between the genotypes. Plane of sections is as in Fig. $1 \mathrm{H}$ and scale bar represents 50 $\mu \mathrm{m}$. cr, crista ampullaris; ed, endolymphatic duct; $f p$, fusion plate; $g$, ganglion; Id, lateral semicircular duct; pd, posterior semicircular duct; sd, superior semicircular duct; u, utricle; us, utriculo-saccular space. 
was strikingly complementary to $N t n 1$ and thus, the reduction of Ntn1 levels in Ntn1-/-embryos could cause an extension of Unc5b expression into neighbouring areas. We compared Unc5b expression in Ntn1-/- embryos $(n=3)$ and wild type littermates at E11.5-12.5 and could not detect any alteration in expression level or distribution. In the outgrowing semicircular ducts, Unc5b was restricted to the tips whereas no expression could be detected in the fusion plate forming areas both in wild type and Ntn1-/embryos (Fig. 1Q,R and data not shown). This showed that the Ntn 1-/-ear phenotype is not derived from an extension of Unc5b expression into the fusion plate.

The Unc5b expression analysis suggested specific roles for this receptor in inner ear sensory development and especially in the developing auditory system. Since no defects have been observed in Ntn 1-/-sensory development (Salminen et al., 2000) Unc5b could play Ntn1 independent roles in these areas. Unfortunately, Unc5b deficient mouse embryos die too early to enable conclusive analysis of inner ear sensory development (Lu et al., 2004).

\section{Integrins in the inner ear}

Since none of the Dcc or Unc5 receptors were co-expressed with Ntn1 in the semicircular duct fusion plate epithelia, Ntn1 could function through other receptors or mechanisms to induce changes in epithelial morphology and to promote detachment of the fusion plate epithelium from the underlying basement membrane. Integrins are heterodimeric cell surface receptors consisting of $\alpha$ and $\beta$ subunits that interact with various extracellular matrix molecules such as laminins, collagens and fibronectin (Reviewed in Kreidberg, 2000). Recently, integrins $\alpha 6 \beta 4$ and $\alpha 3 \beta 1$ have also been shown to bind Ntn1 (Yebra et al., 2003) and all these subunits are produced in inner ear at some developmental stages (Davies and Holley, 2002).

We verified the expression of $1 \operatorname{tga} 3, \lg a 6$, Itgb1 and $1 \operatorname{tg} 64$ during semicircular duct formation at E11.5-12.5 to identify potential Ntn1 interacting subunits. Itga3expression could be detected all over the developing non-sensory vestibular epithelium at E11.5-12.5 (Fig. 2A,B and data not shown). An especially prominent expression was observed in the fusion plate forming epithelia (arrows in Fig. 2A,B). Instead, no expression was detected in the developing sensory areas (white arrowhead in Fig. 2A).

Itga6 was weakly expressed in the tips of the outgrowing semicircular ducts and in the thickened presensory epithelia of the utricle, saccule and cochlea as well as in the outermost cells of the vestibulocochlear ganglion (Fig. 2C,D and data not shown). No expression of Itga6 in the fusion plate epithelium could be observed (arrows in Fig. 2C,D). Itgb1 was expressed all over the otic area including the fusion plate epithelium and the periotic mesenchyme (Fig. 2E,F). In contrast, no expression of /tgb4could be detected (data not shown).

Our expression analysis showed that integrin $\alpha 3 \beta 1$ was the only Ntn1 receptor expressed in the fusion plate epithelium and it could thus play a role in controlling the interactions between the fusion plate and the underlying basement membrane together with Ntn1. Integrin $\alpha 3 \beta 1$ is highly expressed also in many other epithelial cells and it is known to bind mainly to laminin-5 and thought to be involved in organising and stabilising the basement membrane. Inactivation of Itga3 causes a loss of $\alpha 3 \beta 1$, which leads to a thinner and disrupted basement membrane in several organs such as kidney, lung, skin and submandibular gland (Reviewed in Kreidberg, 2000). Ntn1 interaction with integrin $\alpha 3 \beta 1$ could in fact cause a destabilisation of the integrin-laminin interactions and in this way lead to the detachment of the epithelium from the basement membrane.

To verify whether the inactivation of Itga3caused developmental defects in semicircular duct formation we prepared histological sections of $\mathrm{E} 18.5 \mathrm{ltga3}-/(\mathrm{n}=3)$ and control littermate embryos. In all analysed embryos, the semicircular duct formation and growth had occurred normally (Fig. 2G,H) suggesting that Ntn1 can function in fusion plate detachment without integrin $\alpha 3 \beta 1$.

Adhesion defects have been observed when Ntn1 receptors are missing (Ne01-/- mammary glands) or functionally blocked (integrins in pancreatic cell cultures) (Srinivasan et al., 2003; Yebra et al., 2003). No loss of adhesion has however been observed during Ntn 1-/-inner ear development and the adhesion mediating Ntn1 receptors, Neo1 (Srinivasan et al., 2003) and integrin $\alpha 6 \beta 4$ (Yebra et al., 2003) are not present on inner ear epithelium. Instead, we have suggested that high amounts of Ntn1 protein could be required locally for the detachment of the basement membrane underlying the semicircular duct fusion plate epithelium (Salminen et al., 2000). Whether there is a yet unknown «detachment mediating receptor» for Ntn1 in inner ear remains to be identified. Alternatively, Ntn1 may function in a receptor-independent manner and interfere directly with the laminin network (Hedgecock and Norris, 1997; Salminen et al., 2000). Since the other epithelial organs where Ntn1 plays a morphogenetic role do not undergo any fusion events, Ntn1 may play a specific role in inner ear. Interestingly, also other axon guidance cues such as EphB2 and ephrin-B2 have a very specific role in inner ear vestibule, where they control endolymph fluid production (Cowan et al., 2000; Dravis et al., 2007). Thus, both Ntn1 and Eph/ephrin systems critically participate in fine-tuning inner ear morphogenesis. How these factors integrate into distinct regulatory networks controlling inner ear morphogenesis (Reviewed in Fritzsch et al., 2006) is however currently unknown.

\section{Experimental procedures}

\section{Mouse breeding and genotyping}

The breeding of $\mathrm{Ntn} 1+/$ - and $/$ tga3-/-mice and their genotype determination from genomic DNA were performed as before (Kreidberg et al., 1996; Salminen etal., 2000). The embryos were taken from timed matings between two $N$ tn $1+/$-or /tga3 $+/$-mice and the day on which a vaginal plug was detected was assigned as 0.5 . All animal experiments were approved by the Committee of experimental animal research of the University of Helsinki.

\section{RNA in situ hybridization}

For radioactive RNA in situhybridization on paraffin sections, mouse embryos from time-pregnant females were treated and sectioned as described before (Salminen et al., 2000; Lilleväli et al., 2004). The preparation of ${ }^{35} \mathrm{~S}$ labelled riboprobes and the RNA in situ hybridization were carried out as described previously (Salminen et al., 2000). Images where the red colour represents mRNA expression were produced as before (Lilleväli et al., 2004). Non-radioactive RNA in situ hybridisations on dissected whole cochleas from postnatal mice were performed using digoxigenin-UTP (Roche) labelled RNA probes (Wilkinson, 1993) and the stained cochleas were cut radially with vibratome.

The cDNA fragments used to generate Ntn1, Dcc, Neo1, Unc5a, Unc5band Unc5cprobes have been described before (Keino-Masu etal., 
1996; Serafini et al., 1996; Ackerman et al., 1997; Leonardo et al., 1997). Complementary DNA fragments for five additional probes were generated with reverse transcription polymerase chain reaction (RT-PCT) from E12.5 mouse embryonic total RNA and cloned into pGEM-TEasy vector (Promega). The following oligonucleotide primers were used for RT-PCR: Unc5d

forward: 5'-GAACAGCATCAATAGGAATTTATCCG-3' and reverse: 5'-CATATAATAAGTGCTGGTGTCATGTAC-3'.

Integrina3

forward 5'-CTGGAATCTCCTTCAAGACCTTG-3' and reverse 5'-CTACCATCAACATGGAGAACAAG-3',

Integrino6

forward 5'-GAGCAAGCTATGAAATCTGAAGAT G-3' and reverse 5-'CTCTGGCTGCAGGAGAACATCAG-3',

Integrin $\beta 1$

forward 5'-GTGCACAGGAGTGCTCCCACTTC-3' and reverse 5'-GCACACTGTGACCTCAGCAGAC-3',

Integrin $\beta 4$

forward 5'-GGTCCAGGAAGATCCATTTCAACT G-3' and reverse 5'-CATTGGCTGCAGTCATTCTGTGC-3'.

\section{Acknowledgements}

We thank Marc Tessier-Lavigne and Susan Ackerman for in situ probes andforDcc-/- andUnc5c-/- embryos, respectively. We are grateful to Patrick Mehlen and David Goldschneider for Neo1-/- embryos. Raija Savolainen, Lydmula Rasskazova and Christel Pussinen are acknowledged for expert technical assistance. Kersti Lilleväli and Sébastien Duprat are greatly appreciated for critical reading of the manuscript. Grant sponsors: Finnish Academy; Grant number: 207005 (to M.S.); Jusélius Foundation (to M.S.); Viikki Graduate School of Biosciences (to T.M.); EU Marie Curie Early Stage Training; Grant number:MEST-CT-2005-020546 (to M.S. and M.H.).

\section{References}

ACKERMAN, S.L., KOZAK, L.P., PRZYBORSKI, S.A., RUND, L.A., BOYER, B.B. and KNOWLES, B.B. (1997). The mouse rostral cerebellar malformation gene encodes an UNC-5-like protein. Nature 386: 838-842.

BARALLOBRE, M.J., PASCUAL, M., DEL RIO, J.A. AND SORIANO, E. (2005). The Netrin family of guidance factors: emphasis on Netrin-1 signalling. Brain Res. Brain Res. Rev. 49: 22-47.

COWAN, C.A., YOKOYAMA, N., BIANCHI, L.M., HEMKEMEYER, M. and FRITZSCH, B. (2000). EphB2 guides axons at the midline and is necessary for normal vestibular function. Neuron 26: 417-430.

DAVIES, D. and HOLLEY, M.C. (2002). Differential expression of alpha 3 and alpha 6 integrins in the developing mouse inner ear. J. Comp. Neurol. 445: 122-132.

DRAVIS, C., WU, T., CHUMLEY, M.J., YOKOYAMA, N., WEI, S., WU, D.K., MARCUS, D.C. and HENKEMEYER, M. (2007). EphB2 and ephrin-B2 regulate the ionic homeostasis of vestibular endolymph. Hearing Res. 223: 93-104.

FRITZSCH, B., PAULEY, S. and BEISEL, K.W. (2006). Cells, molecules and morphogenesis: The making of the vertebrate ear. Brain Res. 1091: 151-171.
HEDGECOCK, E.M. and NORRIS, C.R. (1997). Netrins evoke mixed reactions in motile cells. Trends Genet. 13: 251-253.

KEINO-MASU, K., MASU, M., HINCK, L., LEONARDO, E.D., CHAN, S.S., CULOTTI, J.G. and TESSIER-LAVIGNE, M. (1996). Deleted in Colorectal Cancer (DCC) encodes a netrin receptor. Ce//87: 175-185.

KENNEDY, T.E., SERAFINI, T., DE LA TORRE, J.R and TESSIER-LAVIGNE, M. (1994). Netrins are diffusible chemotropic factors for commissural axons in the embryonic spinal cord. Cel/78: 425-435.

KREIDBERG, J.A., DONOVAN, M.J., GOLDSTEIN, S.L., RENNKE, H., SHEPHERD, K., JONES, R.C. and JAENISCH, R. (1996). Alpha 3 beta 1 integrin has a crucial role in kidney and lung organogenesis. Development 122: 3537-3547.

KREIDBERG, J.A. (2000). Functions of alpha3beta1 integrin. Curr. Opin. Cel/ Biol. 12: $548-553$

LEONARDO, E.D., HINCK, L., MASU, M., KEINO-MASU, K., ACKERMAN, S.L. and TESSIER-LAVIGNE, M. (1997). Vertebrate homologues of C. elegans UNC-5 are candidate netrin receptors. Nature 386: 833-388.

LILLEVÄLI, K., MATILAINEN, T., KARIS, A. and SALMINEN, M. (2004). Partially overlapping expression of GATA3 and GATA2 during inner ear morphogenesis. Dev. Dyn. 231: 775-781.

LU, X., LE NOBLE, F., YUAN, L., JIANG, Q., DE LAFARGE, B., SUGIYAMA, D., BREANT, C., CLAES, F., DE SMET, F., THOMAS, J.L., AUTIERO, M., CARMELIET, P., TESSIER-LAVIGNE, M. and EICHMANN, A. (2004). The netrin receptor UNC5B mediates guidance events controlling morphogenesis of the vascular system. Nature 432: 179-186.

MARTIN, P. and SWANSON, G.J. (1993). Descriptive and experimental analysis of the epithelial remodellings that control semicircular canal formation in the developing mouse inner ear. Dev. Biol. 159: 549-558.

SALMINEN, M., MEYER, B.I., BOBER, E. and GRUSS, P. (2000). Netrin 1 is required for semicircular canal formation in the mouse inner ear. Development 127: 13-22.

SERAFINI, T., COLAMARINO, S.A., LEONARDO, E.D., WANG, H., BEDDINGTON, R., SKARNES, W.C. and TESSIER-LAVIGNE, M. (1996). Netrin-1 is required for commissural axon guidance in the developing vertebrate nervous system. Cel/87: 1001-1014.

SRINIVASAN, K., STRICKLAND, P., VALDES, A., SHIN, G. and HINCK, L. (2003). Netrin-1/Neogenin interaction stabilizes multipotent progenitor cap cells during mammary gland morphogenesis. Dev. Ce//4: 371-382.

WILKINSON, D. (1993). In: Wilkinson D, editor. Whole-mount in situ hybridization of vertebrate embryos. In situ Hybridization: a Practical Approach. Oxford: IRL Press. p. 75-83.

YEBRA, M., MONTGOMERY, A.M., DIAFERIA, G.R., KAIDO, T., SILLETTI, S., PEREZ, B., JUST, M.L., HILDBRAND, S., HURFORD, R., FLORKIEWICZ, E., TESSIER-LAVIGNE, M. and CIRULLI, V. (2003). Recognition of the neural chemoattractant Netrin- 1 by integrins $\alpha 6 \beta 4$ and $\alpha 3 \beta 1$ regulates epithelial cell adhesion and migration. Dev. Cel/5: 695-707.

Received: 22nd January 2007 Reviewed by Referees: 23rd February 2007 Modified by Authors and Accepted for Publication: 14th May 2007 Published Online: 22 June 2007 


\section{Related, previously published Int. J. Dev. Biol. articles \\ See our Special Issue on Ear Development edited by Fernando Giraldez and Bernd Fritzsch at: http://www.intjdevbiol.com \\ Cell proliferation during the early compartmentalization of the Xenopus laevis inner ear Quincy A. Quick and Elba E. Serrano \\ Int. J. Dev. Biol. (2007) 51: 201-210 \\ New views on retinal axon development: a navigation guide \\ Fanny Mann, William A. Harris and Christine E. Holt \\ Int. J. Dev. Biol. (2004) 48: 957-964}

Axon guidance receptors direct growth cone pathfinding: rivalry at the leading edge. Helen M Cooper

Int. J. Dev. Biol. (2002) 46: 621-631

Functional analysis of FGF3 during zebrafish inner ear development

$\checkmark$ Vendrell, D Gimnopoulos, T Becker, T Schimmang

Int. J. Dev. Biol. (2001) 45: S105-S106

Embryological and genetic aspects of middle ear development.

M Mallo

Int. J. Dev. Biol. (1998) 42: 11-22

Contralateral efferent neurons can be detected in the hindbrain outside of rhombomere 4 .

M Mallo

Int. J. Dev. Biol. (1997) 41: 737-739

Distribution of BDNF and trkB mRNA in the otic region of 3.5 and 4.5 day chick embryos as revealed with a combination of in situ hybridization and tract tracing.

F Hallböök and B Fritzsch

Int. J. Dev. Biol. (1997) 41: 725-732

How does the urodele ear develop?

B Fritzsch

Int. J. Dev. Biol. (1996) 40: 763-771

Role of Raf kinases during inner ear development.

C Sanz, Y Leon, M Garcia-Gil and I Varela-Nieto

Int. J. Dev. Biol. (1996) 40: S83-S84 


\section{Teaching Developmental Biology}

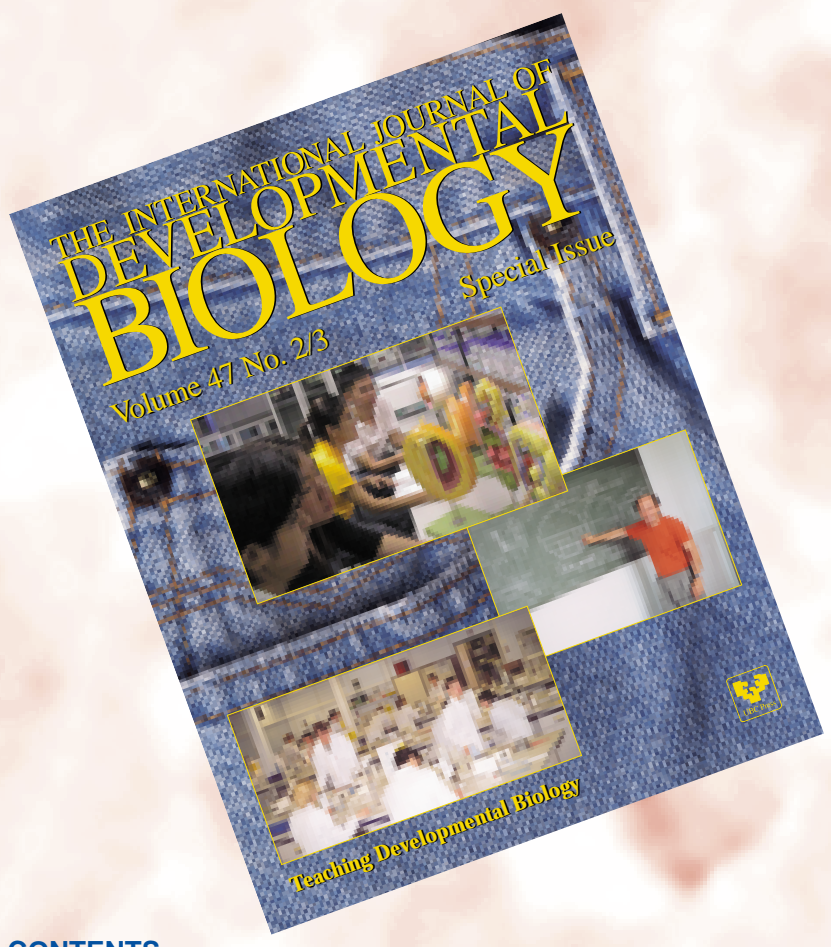

\section{An invaluable resource for researchers with teaching responsabilities!}

\section{CONTENTS}

Introductory Papers

Towards enriching the classroom experience

by George M. Malacinski and Susan T. Duhon

Setting the stage: developmental biology in the precollege classroom

by Sandra Borland, Karen Crawford and Victoria Brand

Examples of Undergraduate Developmental Biology Courses From field to gel blot: teaching a holistic view of developmental phenomena to undergraduate biology students at the University of Tokyo

by Takashi Ariizumi and Makoto Asashima

Integrating developmental biology into the undergraduate curriculum at the University of Bath, United Kingdom by Jonathan M.W. Slack

Making developmental biology relevant to undergraduates in an era of economic rationalism in Australia

by Brian Key and Victor Nurcombe

Learning developmental biology has priority in the life sciences curriculum in Singapore

by Tit-Meng Lim

Developmental biology for undergraduate students at the University of Palermo, Italy

by Giovanni Giudice and Karoly Onorato

Student-oriented learning: an inquiry-based developmental biology lecture course

by George M. Malacinski

Teaching embryology to undergraduates in the Faculty of

Education at Dokuz Eylul University in Izmir, Turkey

by Irfan Yilmaz

Teaching critical thinking in a developmental biology course at an American liberal arts college

by Dany S. Adams

Examples of College Laboratory Courses

Using Xenopus as a model system for an undergraduate

laboratory course in vertebrate development at the University of Bordeaux, France

by Michelle Olive, Pierre Thiebaud, Marc Landry, Michel Duvert, Alain Verna, Wilfrid Barillot and Nadine Theze

The color purple: analyzing alkaline phosphatase expression in experimentally manipulated sea urchin embryos in an undergraduate developmental biology course by Julie Drawbridge

Chick embryo culture techniques employed at Karnatak University in Dharwad, India for studying cellular and molecular aspects of morphogenesis

by Sohan P. Modak

Examples of Advanced and/or Graduate-Level Developmental Biology Courses

An intense half-semester developmental biology course, as taught at Uppsala University, Sweden

by Lennart Olsson

Integrating self-organization theory into an advanced course on morphogenesis at Moscow State University

by Lev V. Beloussov

Reverse engineering the embryo: a graduate course in developmental biology for engineering students at the University of Manitoba, Canada

by Richard Gordon and Cameron A. Melvin

Personal Journeys through Teaching Developmental Biology Developmental biology in Ecuador: a 30-year teaching experience

by Eugenia M. Del Pino

Four decades of teaching developmental biology in Germany by Horst Grunz

My perpetual cycle: from student to researcher to teacher to student...

by Robert Vignali

Course Enhancements and Alternative Learning Strategies Course enhancement: a road map for devising active-learning and inquiry-based science courses

by William $S$. Harwood

The role of textbooks in communicating developmental biology by Leon W. Browder

Using models to enhance the intellectual content of learning in developmental biology

by John C. McLachlan

Virtual labs: a substitute for traditional labs?

by Rebecca K. Scheckler

Broadening the Teaching Agenda beyond Traditional Content Emphases

Educating for social responsibility: changing the syllabus of developmental biology

by Scott F. Gilbert and Anne Fausto-Sterling

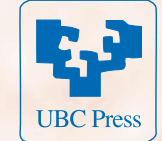

The International Journal of D evelopmental Biology Volume 47 No.2/ 3 (Special Issue) 2003 Order by web at: http:/ / www.ijdb.ehu.es (price 70 US\$ or $€$ ) 